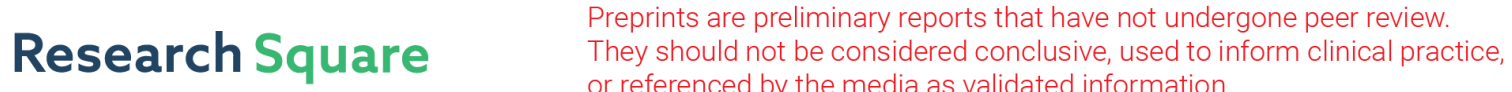 or referenced by the media as validated information. \\ Spatial assessment of tap water safety in China and associated health impacts
}

\author{
Mengjie Liu \\ Research Center for Eco-Environmental Sciences \\ Nigel Graham \\ Imperial College London \\ Wenyu Wang \\ Research Center for Eco-Environmental Sciences, Chinese Academy of Sciences \\ Renzun Zhao \\ North Carolina Agricultural and Technical State University \\ Yonglong Lu \\ Xiamen University \\ Menachem Elimelech ( $\nabla$ menachem.elimelech@yale.edu ) \\ Yale University https://orcid.org/0000-0003-4186-1563 \\ Wenzheng Yu \\ Chinese Academy of Sciences https://orcid.org/0000-0001-9776-8021
}

Article

Keywords:

Posted Date: January 6th, 2022

DOI: https://doi.org/10.21203/rs.3.rs-1166651/v1

License: (c) (1) This work is licensed under a Creative Commons Attribution 4.0 International License.

Read Full License 


\title{
Spatial assessment of tap water safety in China and associated health impacts
}

\author{
Mengjie Liu, ${ }^{\mathrm{a}, \mathrm{b}}$, Nigel Graham ${ }^{\mathrm{c}}$, Wenyu Wang ${ }^{\mathrm{a}}$, Renzun Zhao ${ }^{\mathrm{d}}$, Yonglong Lu ${ }^{\mathrm{e}}$, Menachem \\ Elimelech $^{\mathrm{f}^{*}}$, Wenzheng $\mathrm{Yu}^{\mathrm{a}^{*}}$
}

${ }^{\text {a }}$ State Key Laboratory of Environmental Aquatic Chemistry, Key Laboratory of Drinking Water Science and Technology, Research Center for Eco-Environmental Sciences, Chinese Academy of Sciences, Beijing 100085, China. (wzyu@,rcees.ac.cn)

${ }^{\mathrm{b}}$ University of Chinese Academy of Sciences, Beijing100049, China

${ }^{\mathrm{c}}$ Department of Civil and Environmental Engineering, Imperial College London, South Kensington Campus, London, SW7 2AZ, UK. (n.graham@imperial.ac.uk)

${ }^{\mathrm{d}}$ Department of Civil, Architectural and Environmental Engineering, North Carolina Agricultural and Technical State University, Greensboro, North Carolina, USA 27411(zhao@,ncat.edu)

${ }^{\mathrm{e}}$ State Key Laboratory of Marine Environmental Science and Key Laboratory of the Ministry of Education for Coastal Wetland Ecosystems, College of the Environment and Ecology, Xiamen University, Fujian 361102, China (yllu@xmu.edu.cn, or yllu@,rcees.ac.cn)

${ }^{\mathrm{f}}$ Department of Chemical and Environmental Engineering, Yale University, New Haven, CT, 06520-8286, USA (menachem.elimelech@yale.edu) 


\section{Abstract:}

2 The quality of municipal water supplies is of fundamental importance to public health and national

3 security. Here, we assess the tap water quality in 31 provinces across China and examine the effects

4 of natural and anthropogenic conditions on water quality and associated health risks. Precipitation

5 is a crucial factor influencing the organic matter content and ionic conductivity in tap water,

6 especially for arid and semi-arid regions. Although the concentration of disinfection byproducts

7 (DBPs) is closely related to the organic matter content, the occurrence of highly toxic DBPs was

8 more significantly affected by anthropogenic factors such as economic development and pollution

9 emission. We confirmed nanofiltration as an effective point-of-use treatment to reduce the adverse

10 effects of DBPs in public water supplies. Since DBPs in tap water is a long-term global problem,

11 our results highlight the potential health hazards of drinking water brought about by social

12 development and conclude that countries and regions with rapid development might face high DBP

13 toxicity.

14 


\section{Introduction}

The provision of safe and reliable supply of drinking water is of fundamental importance to society ${ }^{1,2}$. According to the World Health Organization (WHO), the sixth goal for sustainable development in accordance with Agenda 2030 is water quality. Conventional water treatment by coagulation-sedimentation-filtration-disinfection, the most widely used drinking water treatment process in China, can remove 10\%-60\% of dissolved organic matter (DOM) ${ }^{3,4}$. However, disinfection byproducts (DBPs) are formed from the reaction between chlorine-based disinfectants and DOM; these byproducts are associated with adverse health outcomes (e.g. bladder cancer), as reported in epidemiological and toxicological studies ${ }^{5-9}$. The adverse health outcomes associated with DPBs represent a long-term public health problem with regard to drinking water ${ }^{10}$.

While several studies have evaluated the occurrence of DBPs in tap water, these studies were conducted mainly in local regions and cities ${ }^{11-13}$. Only a limited number of nationwide DBP 27 surveys have been reported - in the UK ${ }^{14}$, the USA ${ }^{15}$ and China ${ }^{16}$ — approximately a decade ago. In China, the regular monitoring of drinking water quality is carried out by local authorities (Water Supply Bureaus), but this typically includes only routine parameters such as turbidity and $\mathrm{pH}$. As a consequence, statistical data related to national tap water quality, especially exposure to DBPs via tap water and the impact of DBPs on public health, remain unclear and elusive.

China has a large land area of more than 9.6 million square kilometers, with tremendous

33 variations in climate, topography, population density and level of economic development. These

34 differences might lead to diverse composition of DOM in soil and water in different regions. For

35 instance, climate has been found to account for the majority of soil DOM heterogeneity ${ }^{17}$, and to

36 determine the regional variation of the forest carbon stock ${ }^{18}$. Considering that about one-quarter

37 of the net carbon fixation on land enters the dissolved organic carbon (DOC) pool of natural waters

$38{ }^{19}$, the impact of climate stress on water quality is inevitable. In addition to natural factors, human 39 activities have also resulted in environmental challenges; this connection is referred to as the 40 coupling between economic prosperity and ecological impact ${ }^{20}$. A recent study has indicated that 
41 lakes in China's populated regions are facing an imbalance of nitrogen and phosphorus due to the

42 discharge of domestic sewage ${ }^{21}$. While these studies have shown the effects of environmental

43 stressors on soil or natural waters, it is unclear whether the variations in natural conditions and

44 human activities have significant effects on the quality of tap water.

45 In this study, we conducted a comprehensive analysis of the quality of tap water samples from

4631 provinces in China (excluding Hong Kong, Macao and Taiwan) (Figure S1). Our study

47 provides answers to the following questions: (i) What is the spatial distribution of tap water quality

48 across China? (ii) What are the correlations between natural and anthropogenic factors and tap

49 water quality distribution? (iii) Do spatial differences in tap water quality lead to health risk

50 disparity? (iv) How might we deal with the health risks of poor-quality tap water? This is the first

51 study to discuss water safety issue at a large spatial scale. The results of this study generate a

52 unique database of national tap water quality, particularly DBPs, and provide a prima facie insight

53 on the relationship between multiple factors and drinking water safety.

55 Results

\section{Precipitation has a dual effect on total organic carbon}

Total organic carbon (TOC) was used to evaluate the organic content of tap water; the distribution pattern is shown in Figure 1a. The TOC of tap water in different regions was greatly

59 affected by the quality of local water sources. According to the national surface water quality report

60 (http://www.cnemc.cn/jcbg/qgdbsszyb/), surface water pollution was the most serious in Songhua

61 River and Hai River (Figure 1b), with 36.4\% and 38.8\% monitoring points, respectively, not

62 suitable for domestic drinking water source (water quality > III, the Environmental Quality

63 Standards for Surface Water are shown in SI, Table S1). As a consequence, high TOC values were

64 observed in the Songhua River Basins. However, the levels of TOC in the Hai River Basin were

65 relatively lower than those in surrounding areas, because most cities in the Hai River Basin used

66 water from the Changjiang River as water source rather than local source waters. This pattern of 
use is known as the South-to-North Water Diversion Project (Figure S2). It was reported that in 2020 the middle route of the South-to-North Water Diversion project (eastern, middle and western routes) supplied 8.3 billion cubic meters of water for Beijing, Tianjin as well as more than 20 large and medium-sized cities in Henan and Hebei provinces. Therefore, the water diversion engineering

71 works have not only significantly relieved the water resource pressure of the Hai River Basin ${ }^{22,23}$,

72 but also improved the drinking water quality in these receiving areas.

73 In addition to the TOC differences caused by different water sources, the accumulation of 74 organic matter along the same river also led to an increase of TOC from upstream to downstream.

75 For instance, the TOC was observed to increase gradually along the main stream of the Changjiang

76 (Yangtze) River (Figure S3), the longest and largest river in China, which suggests accumulation

77 of DOM when pollution exceeds the self-purification capacity of the water body. Moreover, the

78 intense human activity (Figure S4) in eastern regions resulted in more nutrient pollutants (e.g.

79 phosphorus and nitrogen) from domestic wastewaters to water bodies, and thus the microbial

80 activity in these water bodies was significant ${ }^{24}$. A previous study found an increase of low-

81 molecular-weight organics from upstream to downstream of the Changjiang River; the main

82 component of organics changed from humic substances with terrestrial origins to microbial-

83 derived protein-like biopolymers ${ }^{25}$. The latter were more difficult to remove in drinking water

84 treatment ${ }^{26}$. Therefore, the variation of DOM composition is also responsible for the higher TOC

85 value in eastern regions.

86 Precipitation is another crucial natural factor that accounts for the variation of TOC.

87 Precipitation has a dual effect on TOC: (1) atmospheric particulate matter and soil organic matter

88 can be scavenged by precipitation and contribute DOM to runoff waters, and (2) conversely, heavy

89 precipitation can dilute the DOM in the runoff waters. From the correlation between precipitation

90 and the TOC of tap water (Figure 1c), it can be seen that TOC increases with precipitation for the

91 northern samples, but changes little with precipitation in the southern samples. The boundary

92 between northern and southern China follows the Qinling-Huai River line, which coincides with 
93 the $800 \mathrm{~mm}$ precipitation line that divides humid and sub-humid regions (Figure S5). For northern

94 cities, TOC has a significant positive correlation with precipitation due to DOM scavenging from

95 soil and atmosphere. In contrast, the dilution effect offsets the DOM scavenging in southern cities,

96 and the TOC variation is much smaller than that within northern cities.

97
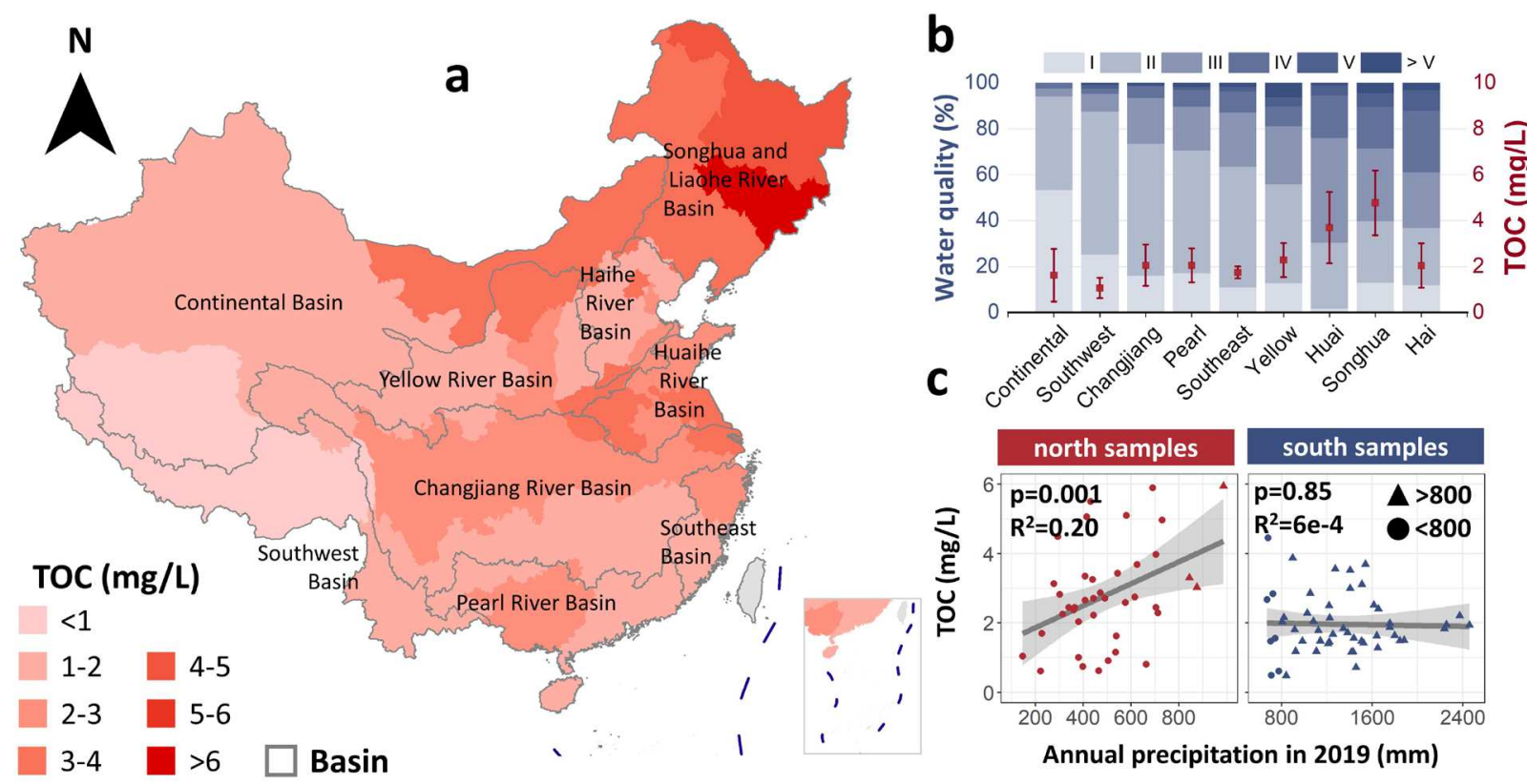

99 Figure 1. TOC in tap water. (a) Spatial distribution of TOC (averaged by province) in China. (b) Surface water quality and the average TOC in nine basins. Detailed information about the water quality level (I-V and >V) appears in SI, Table S1. (c) Variation of TOC with annual precipitation (in 2019), where the grey line is the linear fitting of results. The color indicates the annual precipitation (blue: $>800 \mathrm{~mm}$, red: $<800$ $\mathrm{mm}$ ), and the shape indicates the location (triangles: south; circles: north).

\section{Soil erosion and seawater intrusion lead to high ionic conductivity of tap water}

The variation of electric conductivity in tap water across China is shown in Figure 2a. Among

107 the eight regions, middle Yellow River (MYR) and north coast (NC) have relatively higher 108 conductivity (Figure $2 \mathrm{~b}$ ). Considering that conventional drinking water treatment has little effect 109 on the removal of background ions, the variation in conductivity is mainly ascribed to different 110 water sources. Tap water using Yellow River (YR) or underground water (UW) as water sources 111 has significantly higher conductivity than others (OT) (Figure S6), and cities with such levels of 
112 water conductivity were mainly located in the north-west (NW), middle Yellow River (MYR) and 113 north coast (NC) regions. However, Henan province (tagged in Figure 2a), with water from the 114 South-to-North Water Diversion project as part of its drinking water source (Figure S2), was found 115 to have a lower conductivity than other provinces located at the middle Yellow River region, which 116 once again proved that the south-to-North Water Diversion project has improved the tap water 117 quality of cities along its route.

118 The Yellow River basin is known to experience intense soil erosion due to the combined 119 impact of natural processes and human activity ${ }^{1}$. The annual runoff of the Yellow River (Tongguan 120 Hydrological Station) in 2019 was 41.56 billion cubic meters, with 168 million tons of annual 121 sediment load (equivalent to an average concentration of $\sim 4 \mathrm{~g} / \mathrm{L}$ ). According to the monitoring 122 data of the gauging stations from 2009 to 2019 , the sediment load increased markedly in the middle 123 reach of the river as it crosses the Loess Plateau (Figure 2c) ${ }^{27}$, and a similar large rise in 124 conductivity (for samples using Yellow River as a water source) was also evident in this region. 125 Loess Plateau, located in the arid and semi-arid region of China, is an important inorganic carbon 126 (calcium carbonate) reservoir, and its soil inorganic carbon (SIC) stock was calculated to be 2.1 127 times greater than its soil organic carbon (SOC) stock ${ }^{28}$. Therefore, it is likely that inorganic 128 carbon was introduced to the Yellow River through soil erosion and led to the increase of calcium 129 in the river. As shown in Figure S7, calcium ions were the main metal ions in tap water, accounting 130 for $54.5 \%$ of the total metal ion concentration. For coastal regions, seawater intrusion and soil 131 salinization were responsible for high conductivity. According to the Bulletin of China Marine 132 Disaster (http://www.mnr.gov.cn/sj/sjfw/hy/gbgg/zghyzhgb/), seawater intrusion is serious in the 133 coastal plain area of the Bohai Sea, and the extent of intrusion increased from 2015 to 2018. In 134 contrast, the extent of intrusion in most coastal areas of the Yellow Sea, the East China Sea and 135 the South China Sea was relatively small. As a result, Liaoning, Hebei, Shandong and Jiangsu 136 provinces were found to have higher conductivity than other coastal provinces. Conductivity was 137 found to decrease with precipitation in both northern and southern China (Figure 2d). Considering 
138 that the TOC increased with annual precipitation in northern China, we deduced a negative 139 relationship between TOC and conductivity in this region. Previous studies have suggested that 140 when the landscape varied from desert to forest along a precipitation gradient, the root biomass 141 and SOC content increased considerably, while the SIC content significantly decreased ${ }^{29}$. Our 142 study found that this conclusion not only applied to soils, but also to tap water in arid and semi143 arid regions, indicating the connection between the soil and water environments.
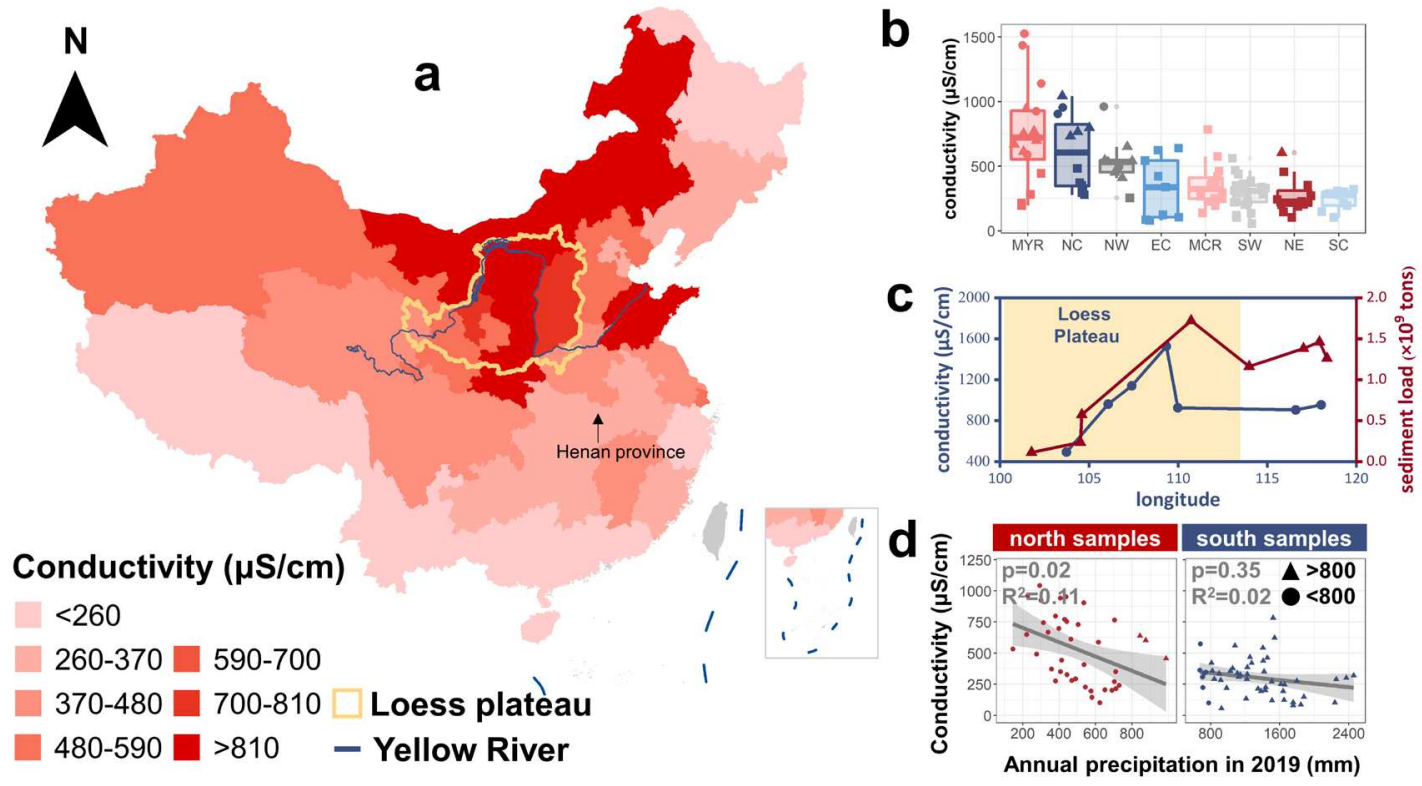

Figure 2. Conductivity in tap water. (a) Spatial distribution of tap water conductivity (averaged by province) in China. (b) Boxplot of conductivity in eight economic regions. The shape of points indicates the water sources, and the color indicates eight economic regions: north-east (NE), north coast (NC), east coast (EC), south coast (SC), middle Yellow River (MYR), middle Changjiang River (MCR), north-west (NW), south-west (SW), where boundaries are shown in the SI, Figure S1. (c) The conductivity of tap water using the Yellow River as the water source (blue), and the sediment load of the Yellow River at the main gauging station (red). The $x$-axis is the longitude of sampled cities and the gauging stations. The sediment load data were ten-year averages (2009-2019) from the China River Sediment Bulletin (2019). (d) Variation of conductivity with annual precipitation (in 2019), where the grey line is the linear fitting of results. The color indicates the annual precipitation (blue: $>800 \mathrm{~mm}$, red: $<800 \mathrm{~mm}$ ), and the shape indicates the location

155 (triangle: South; circle: North). Note: $810 \mu \mathrm{S} / \mathrm{cm}$ is equivalent to $518 \mathrm{mg} / \mathrm{L}$ total dissolved solids (TDS).

\section{DBP concentrations vary widely across China}

158 At present, trihalomethanes (THMs) and haloacetic acids (HAAs) are the two most detected and 
159 regulated groups of DBPs, although hundreds of other DBPs have been identified and some are of 160 greater potential toxicity ${ }^{30-34}$. In this study, four THMs, seven HAAs and four nitrogen-containing

161 DBPs (N-DBPs) were detected in tap water samples from 103 cities; the spatial distribution of 162 these three kinds of DBPs are shown in Figures S8-S10. The average totals of THMs, HAAs and 163 N-DBPs were $54.82 \mu \mathrm{g} / \mathrm{L}, 16.07 \mu \mathrm{g} / \mathrm{L}$ and $3.85 \mu \mathrm{g} / \mathrm{L}$, respectively (Figure $3 \mathrm{a}$ ). We found that $88.3 \%$ 164 of the samples were below the THMs maximum level for drinking water in China (100 $\mu \mathrm{g} / \mathrm{L})$, and $165100 \%$ of the samples met the requirement for HAAs. The north-east (NE) region exhibited the 166 highest concentration of total DBPs, followed by middle Changjiang River (MCR) and coastal 167 regions. In contrast, the western regions (north-west (NW), south-west (SW) and middle of Yellow 168 River (MYR)) had relatively lower DBP concentrations, which is partially due to the water sources 169 in those regions being mainly underground water with fewer DBP precursors ${ }^{35}$. Among the four 170 largest cities, Beijing, Guangzhou and Shenzhen were found to have high DBPs (Figure 3c). 171 Shanghai, located at the estuary of the Changjiang River, however, had a very low DBP 172 concentration. According to the "13th Five-Year Plan of Shanghai Water Supply System", 173 Shanghai is conducting a program of upgrading its water treatment and supply facilities. By the 174 end of $2020,60 \%$ of the city's water plants had adopted the combination of ozone and biological 175 activated carbon (biofiltration) for enhanced water treatment. Ozone-biofiltration has been shown 176 to significantly decrease DBP precursors in previous studies ${ }^{36-38}$. Other treatment processes such 177 as advanced oxidation (e.g. $\mathrm{O}_{3}, \mathrm{O}_{3}-\mathrm{H}_{2} \mathrm{O}_{2}, \mathrm{UV}-\mathrm{H}_{2} \mathrm{O}_{2}$ ), nanofiltration and their combination were 178 also reported to lower the DBP formation potential prior to chlorination ${ }^{39-41}$. These results 179 highlight the fact that advanced or extended treatment is necessary for the control of DBPs in tap 180 water. This economically viable conclusion should be promoted in other first-tier or second-tier 181 cities facing the risk of high DBP formation. 


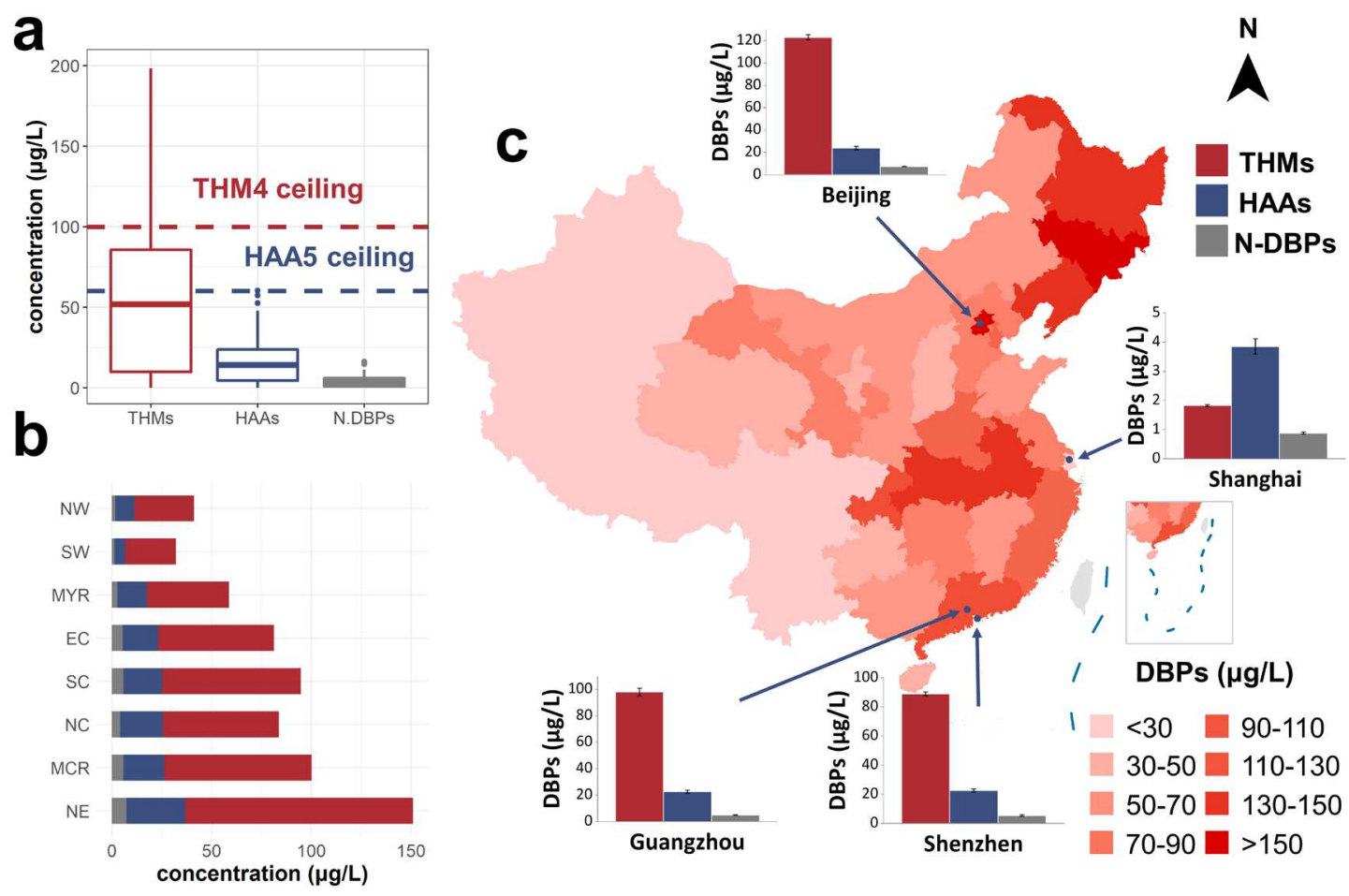

184 Figure 3. Occurrence of DBPs in tap water samples. (a) Boxplots of three categories of DBPs (total THMs, 185 HAAs and N-DBPs) in tap water samples of 103 cities. (b) Average concentrations of THMs, HAAs and N186 DBPs in eight economic regions (see caption of Figure 2 for the names of the economic regions). The color 187 indicates different DBPs: THMs (red), HAAs (blue) and N-DBPs (grey). (c) Spatial distribution of DBP 188 concentration (averaged by province) in China as a whole and in its four largest cities.

190 Areas with high bladder cancer incidence have higher concentrations of DBPs

191 High exposure to DBPs was reported to be related to adverse health outcomes ${ }^{42,43}$. A landmark

192 study three decades ago concluded that exposure to DBPs in drinking water is associated with 10$19340 \%$ excess risk of cancers of the bladder, colon and rectum ${ }^{44}$. Since then, numerous 194 epidemiological studies were conducted to reveal the association between chlorinated DBP 195 exposure and specific cancer outcomes; the studies have aroused considerable concern ${ }^{45}$. Most of 196 these studies used a case-control method focused on individuals, concluding that the case group 197 had higher DBP exposure than the control group.

198 In this work, we discussed this issue from the spatial perspective. We took a closer look at 46 199 cities with both tumor registration information (from China's cancer registry annual report (2018)) 
200 and DBPs data (measured in this study), and found that cities with a higher incidence rate for

201 bladder cancer were characterized by higher DBP concentration in tap water (Figure 4a-4c).

202 Specifically, 20 cities with an age-standardized rate (ASR) higher than the national average had a

203 median DBP concentration of $103.43 \mu \mathrm{g} / \mathrm{L}$, which was significantly higher than the remaining 26

204 cities with a median DBP concentration of $71.45 \mu \mathrm{g} / \mathrm{L}(\mathrm{p}<0.01$, Wilcoxon test $)$. Linear regression

205 further showed a log-linear relationship between the concentration of DBPs and the bladder cancer

206 incidence (Figure 4d-4f). When considering the gender difference, males had a higher incidence

207 of bladder cancer than females, but both rates were strongly associated with the concentration of

208 DBPs. The relationships between DBPs and rectal and colon cancers were also considered (Figure

209 S11); however, the statistical results are only on the verge of significance. Unlike consistent

210 association between DBP exposure and bladder cancer risk, results for colon and rectal cancers

211 were controversial ${ }^{46}$.

212 It should be emphasized that, considering the lack of a large sample size, the above discussion

213 only highlights the potential link between DBPs in tap water to bladder cancer. Other confounding

214 variables such as tobacco consumption, dietary and genetic factors are also responsible for cancer

215 disparities ${ }^{45}$. More detailed studies are needed to understand which populations or regions in

216 China are more vulnerable to the health impacts of DBPs. 

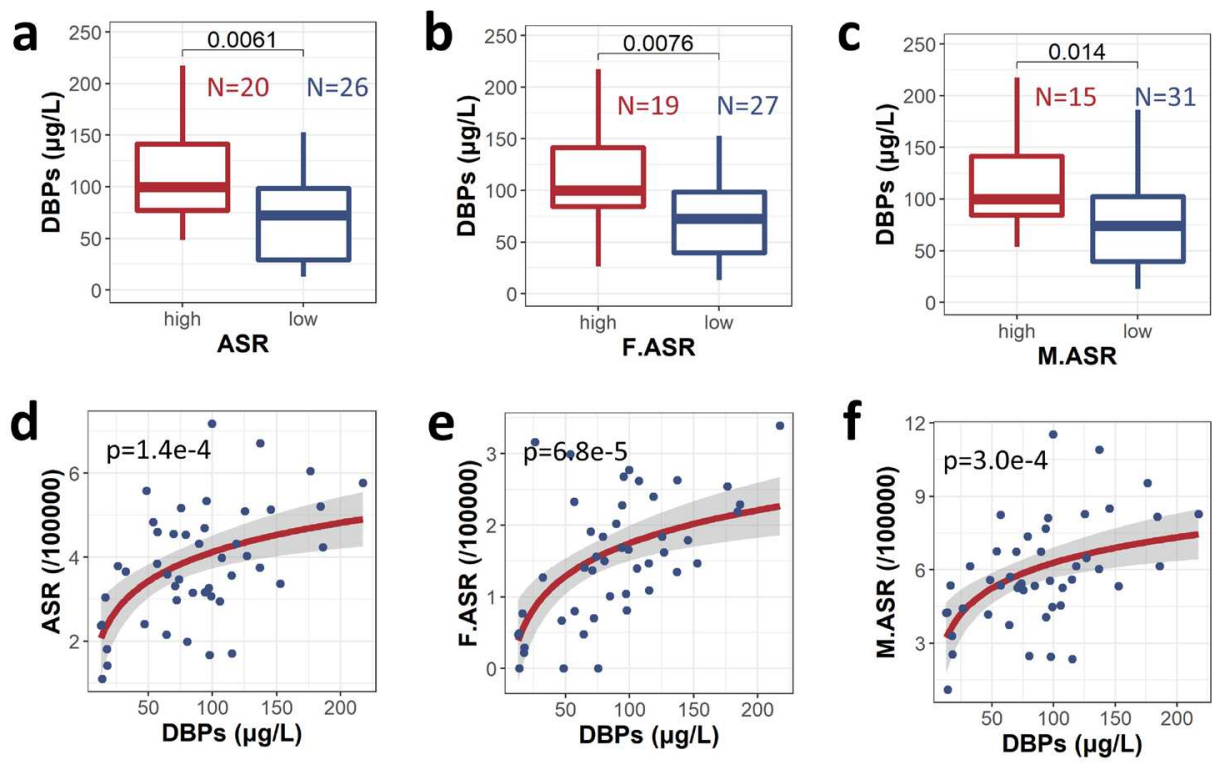

218 Figure 4. DBP association with bladder cancer. (a-c) Comparison of DBP concentrations for cities with bladder cancer rate higher (high group) or lower (low group) than the national average: (a) all gender, (b) female, (c) male. Results from Wilcoxon tests showed significant differences $(p<0.05)$ between high group and low group. Details of cancer rates in 46 cities were provided in SI, Table S2. (d-f) Scatter plot showing the correlation between bladder cancer indexes and DBP concentration, where the red line is the logarithmic linear fitting of results: (d) all gender, (e) female, (f) male. The cancer indexes are: ASR-age standardized rate, F.ASR-female age standardized rate, M.ASR-male age standardized rate.

\section{The cytotoxicity level of DBPs shows spatial aggregation}

226 In addition to the cancer risk, DBPs were also reported to have cytotoxicity. Based on the

227 lethal concentration 50\% (LC50) value from a previous study ${ }^{47}$, the total toxicity of DBPs in tap 228 water samples was calculated (see Methods). The north coast (NC) and east coast (EC) regions 229 were found to have the greatest DBP toxicity risk (Figure 5a). Global spatial autocorrelation 230 (Moran's I) suggested that the total toxicity was spatially aggregated (SI, Figure S12). A Local

231 Moran statistic was constructed to further identify local clusters and local spatial outliers of DBP 232 total toxicity (Figure 5b). Shandong, Jiangsu, Zhejiang and Anhui provinces were the cores of a 233 high-high cluster, while Xinjiang, Tibet, Qinghai, Sichuan and Yunnan provinces were the cores 234 of low-low cluster. Nonetheless, Shanghai (high-low point) and Chongqing (low-high point) were 235 two spatial outliers, suggesting the total toxicity was significantly lower (in Shanghai) or higher 
236 (in Chongqing) than their adjacent provinces. As discussed earlier, Shanghai had substantially low

237 DBP concentration due to its wide adoption of advanced treatment processes. Chongqing, one of 238 the four municipalities directly under the central government, is the largest industrial and 239 commercial city in southwest China. The higher level of DBP toxicity observed here indicated that 240 anthropogenic factors also affected the water quality, which will be discussed in the subsequent 241 section.

\section{Anthropogenic factors are strongly linked to DBP toxicity}

243 The above discussion involved TOC, conductivity, DBPs and DBP toxicity. The heat map

244 shown in Figure S13 depicts the Pearson coefficients between each two water quality indexes, 245 with the indexes being ordered via hierarchical clustering. The results show that toxicity was 246 highly correlated with Br-containing DBPs (Br-DBPs), while the correlation between TOC and 247 non-brominated DBPs (Cl-DBPs) was greater (Figure S14). Therefore, although most organic 248 matter formed Cl-DBPs during chlorination, the Br-DBPs with lower concentration contributed 249 more to the total toxicity of DBPs. When considering the effect of natural and anthropogenic 250 factors on water quality, we found a negative relationship between conductivity and natural factors 251 such as annual precipitation and forest coverage, while anthropogenetic factors such as gross 252 domestic product (GDP) and waste emission showed a significant positive relationship with DBP 253 toxicity (Table S4). Therefore, partial least squares path modeling (PLS-PM) analysis was further 254 performed to examine the complex relationships among two natural factors, ten anthropogenic 255 factors, three DOM indexes, conductivity, six Cl-DBPs, nine Br-DBPs and the total toxicity of 256 DBPs (Figure 5c, Figure S15 and Table S4). The DBP toxicity was more significantly affected 257 by Br-DBPs than Cl-DBPs. A previous study also showed that both cytotoxicity and genotoxicity 258 were highly correlated with total organic bromine, but were weakly or inversely correlated with 259 total organic chlorine ${ }^{48}$. In contrast, DOM had a stronger and more significant effect on Cl-DBPs 260 than Br-DBPs. The effects of conductivity on the concentration of Cl- and Br-DBPs were opposite. 261 A possible reason is that areas with high conductivity, such as coastal regions, had a high 
concentration of bromide in their water environment due to seawater intrusion or bromine

263 industrial production, thus promoting the formation of Br-DBPs during chlorine-based disinfection

$264{ }^{35}$. Natural factors (precipitation and forest coverage rate) had weak correlation with DBP 265 concentration and toxicity. In contrast, anthropogenic factors were significantly correlated with 266 Br-DBPs, and therefore had a strong indirect effect on DBP toxicity (Figure 5d). This result 267 implies that human activities, such as industrial manufacturing, might change the properties of 268 DOM in water and lead to the increase of DBP toxicity in drinking water. As a consequence, 269 countries or regions with rapid economic development and high pollution emissions might face a 270 higher risk of DBP toxicity exposure. Therefore, potential health hazards in drinking water caused 271 by social development should be emphasized in future studies.
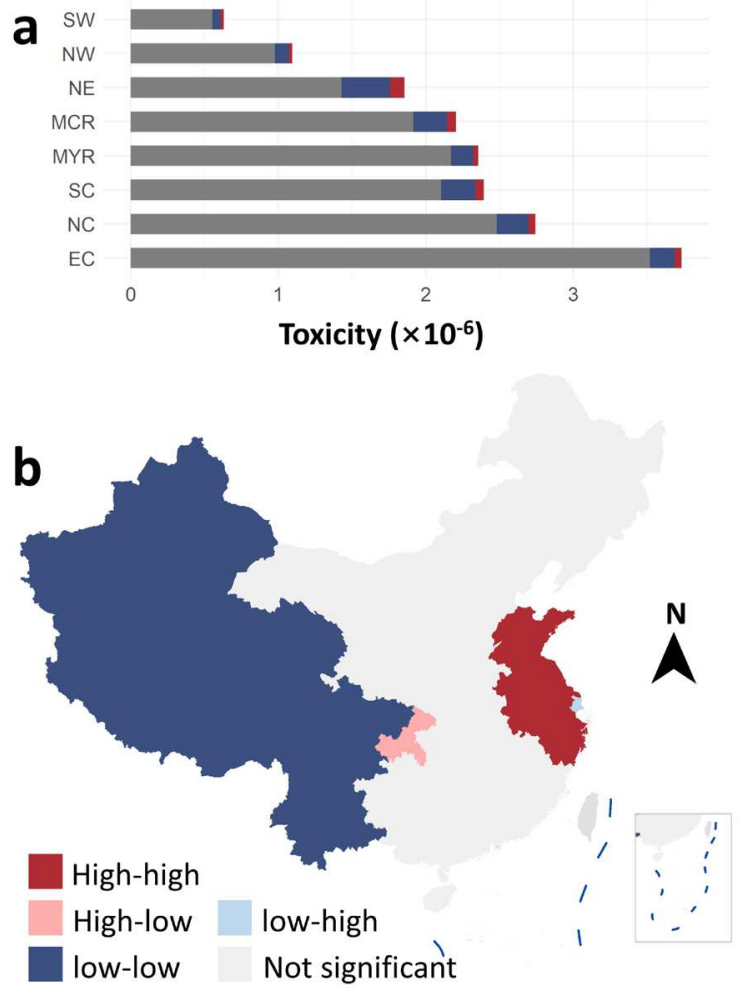
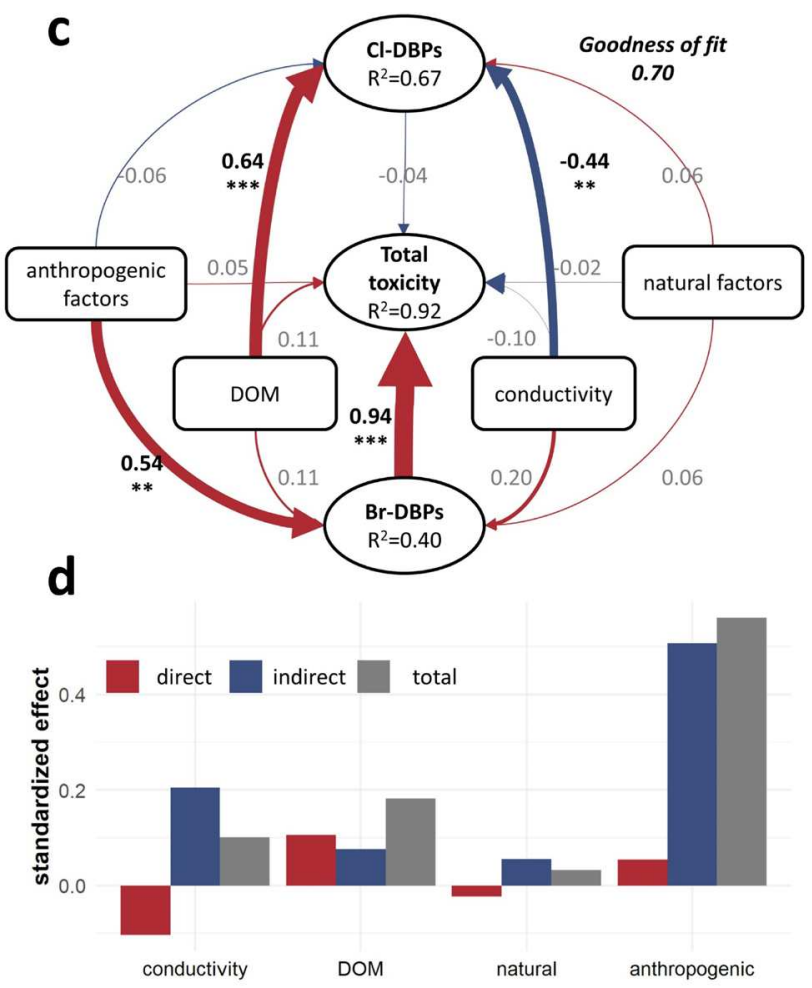

274 Figure 5. Calculated DBP cytotoxicity. (a) Average toxicity of THMs, HAAs and N-DBPs in eight economic 275 regions. The color indicates different DBPs: THMs (red), HAAs (blue) and N-DBPs (grey). (b) Local Moran 276 cluster map of DBP total toxicity. Strictly speaking, the locations shown as significant on the significance 
and cluster maps are not the actual clusters, but rather the cores of a cluster. In contrast, in the case of spatial outliers, the locations are the actual locations of interest; (c) PLS-PM describing the relationships between water quality and environmental factors. The composite variable DOM, natural factors, social factors, Cl-DBPs and Br-DBPs are explained in Table S4. Larger path coefficients are shown as wider arrows, and blue and yellow colors indicate positive and negative effects, respectively. Path coefficients and coefficients of determination $\left(R^{2}\right)$ were calculated after 999 bootstraps, and significance levels are indicated by ${ }^{* * *} p<0.001,{ }^{* *} p<0.01$ and ${ }^{*} p<0.05$. The degree of fit was 0.70 ; (d) Standardized direct and indirect mean effects on total toxicity derived from the partial least-squares path models.

\section{Geographically close regions have similar water quality}

Principal component analysis (PCA) was conducted to demonstrate the relationship between samples from different regions (Figure 6a). The aforementioned indexes (TOC, conductivity, 15 DBP compounds and DBP toxicity) as well as indexes calculated from UV-visible spectra and excitation-emission matrix (EEM) spectrofluorometery (Table S3) were included. We observed that TOC, total fluorescence (TF), A245 and most chlorinated DBPs are distributed along the first

292 principal axis, while most brominated DBPs, DBP toxicity and conductivity clustered at the second 293 principal axis, which was inconsistent with the results in Figure 5a. The samples were 294 geographically divided into eight regions as before. North-west (NW, dark grey) and south-west 295 (SW, light grey) samples were primarily clustered at the third quadrant, suggesting they had relatively lower concentrations of DBPs and DOM. North-east (NE, dark red) samples, located at

297 the positive side of the first principal axis, had a significantly higher concentration of chlorinated

298 DBPs and DOM than other regions. Samples from coastal regions (especially for the east coast

299 (EC)) had a higher value at the second principal component, implying they had more brominated

300 DBPs and exhibited greater DBP toxicity. For coastal regions, the landward expansion of seawater

301 or underground salt water (directly related to seawater) along an aquifer might elevate the bromide

302 concentration in the drinking water source, and result in more Br-DBP formation and greater total 303 toxicity ${ }^{35,48}$. Moreover, Shandong province and Jiangsu province dominate the production of 304 brominated chemical products such as brominated flame retardant ${ }^{49}$. A previous study observed 305 relatively high concentrations of brominated flame retardant in the rivers near Laizhou Bay ${ }^{50}$, 
which is one of three bays in the Bohai Sea and the largest bay in Shandong Province. Therefore,

307 the brominated chemical products in surface water may not only cause adverse effects to human

308 health by direct exposure ${ }^{51}$, but also by increasing the possibility of higher Br-DBPs formation as

309 well as the associated DBPs toxicity.

310 Permutational multivariate analysis of variance (PERMANOVA) was used to further evaluate

311 the significance of differences among the eight regions (Figure 6b). North-east (NE) and south-

312 west (SW) samples showed significant differences from samples from other regions. However,

313 there were some linkages between the remaining six regions: (1) northern samples (NW, MYR,

314 NC connected by Yellow River); (2) eastern samples (NC, MCR and EC connected by Changjiang

315 River and the South-to-North Water Diversion Project); (3) southern samples (EC, SC and MCR

316 connected by waterbodies in the middle and lower reaches of Changjiang River) exhibited

317 insignificant differences. These results imply that geographically close areas tend to exhibit similar

318 water quality. The correlation between water quality and geographical location is demonstrated in

319 Figure 6c. Here, we used two indexes (namely, 'north' and 'east' calculated by the method 320 described in SI, Text S3) to describe the relative location of the sample point in China, with higher

321 value indicating farther north or east. We saw that the 'east' index had a more significant

322 correlation with all water indexes except for conductivity, suggesting that the east-west divide in

323 water quality is more pronounced than the north-south divide. The conductivity of tap water was

324 greatly affected by precipitation, and therefore significantly correlated with 'north' as discussed

325 above. The results of multiple linear regression suggested that geographical location can explain

$32618.9 \%$ to $47.0 \%$ of the variation in different water indexes. TOC had the highest explained variance,

327 while DBP concentration is affected by the water treatment and disinfection parameters

328 (disinfectant type and dosage), and thus had a lower explained variance. 
a

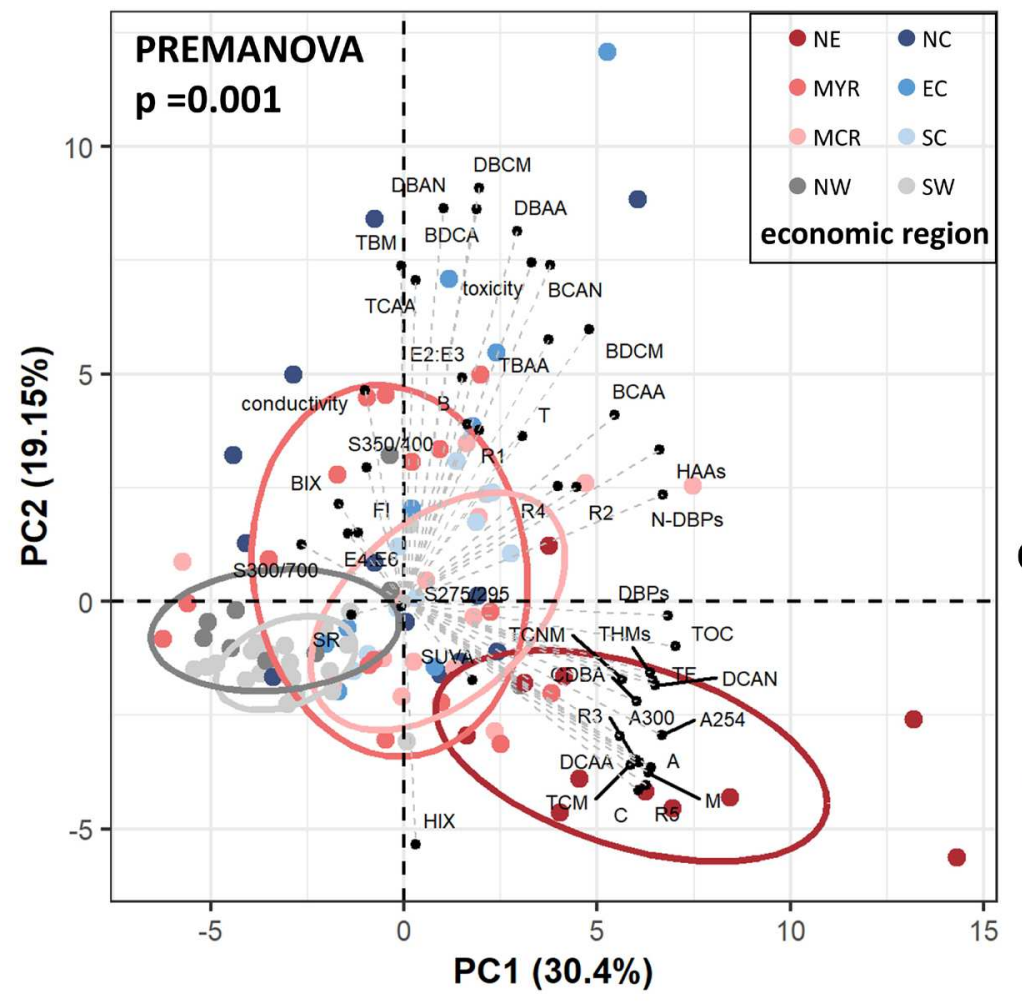

b $0.001 \quad 0.01-0.001 \quad 0.05-0.01 \quad>0.05$

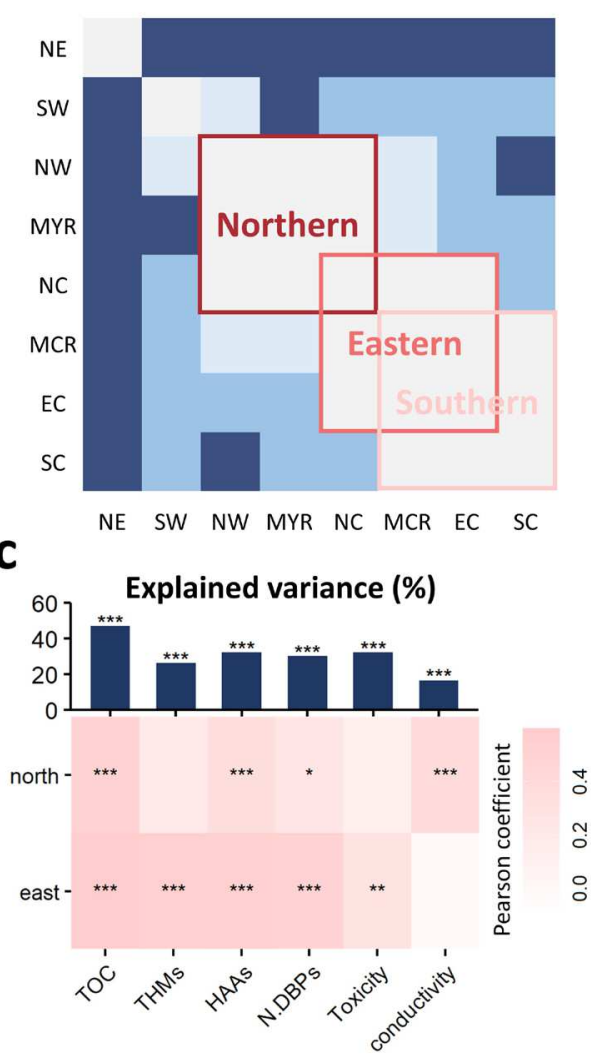

\section{3}

Figure 6. Overview of water quality and environmental factors. (a) PCA analysis of water quality index. The color of points indicates different regions. The indexes include total organic carbon (TOC), UV absorbance at $254 \mathrm{~nm}\left(\mathrm{~A}_{254}\right)$ and $300 \mathrm{~nm}\left(\mathrm{~A}_{300}\right)$, specific UV absorbance (SUVA), ratio of absorbance at $250 \mathrm{~nm}$ to 365 $\mathrm{nm}$ (E2:E3), total fluorescence (TF), five specific TF (R1-R5), humification index (HIX), biological index $(B I X)$, fluorescence index $(F I)$, and EEM peaks $(A, B, C, M, T)$. The explanations of these water quality indexes are summarized in Table S3. (b) Difference in water quality indexes in eight regions by permutational multivariate analysis of variance (PERMANOVA), where the color denotes the significance level. (c) Contribution of geographical location (north and east direction) to water qualities based on correlation and multiple regression models. The heat map shows the Pearson correlation coefficients for geographical location and water quality. The asterisks denote the significance levels: ${ }^{* * *} p<0.001,{ }^{* *} p<$ 0.01 and ${ }^{*} p<0.05$. The bar plot shows the total contribution of geographical location to the interpretation of water qualities (obtained by multiple linear regression).

\section{Nanofiltration effectively improves water quality}

With the deterioration of the quality of water resources and the heightened demand for highquality drinking water, interest in using domestic water purifiers to improve tap water quality and reduce adverse health effects has been growing rapidly in recent years ${ }^{52}$. Compared to 
347 conventional water treatment, membrane filtration can produce water of significantly higher 348 quality with no chemical addition. Here, we used two nanofiltration membranes with different 349 rejection rates (namely, NF270 and NF90) to test the improvement in water quality by 350 nanofiltration. The results (Figure 7a) show that NF270 and NF90 on average decreased 351 conductivity by $12.8 \%$ and $57.7 \%$, respectively. In conventional drinking water treatment, 352 hydrophobic substances with large molecular weight are readily removed ${ }^{53}$, leaving small and 353 hydrophilic substances in the treated drinking water; such substances are difficult to retain by 354 hydrophilic NF membranes ${ }^{38}$. Therefore, the removal rate of TOC was only $20.5 \%$ and $55.2 \%$ for 355 NF270 and NF90, respectively. For DBPs, although their molecular weights (MW) are very low $356(<300 \mathrm{Da})$, their hydrophobic nature resulted in a high removal rate by nanofiltration, with $66.2 \%$ 357 and $78.2 \%$ for NF270 and NF90, respectively.

358 The removal rates of 15 DBP compounds are shown in Figure $7 \mathrm{~b}$. Generally, molecules with 359 more halogen atoms had a higher retention rate, and Br-DBPs were easier to remove than Cl-DBPs 360 for DBPs with identical halogenation degrees due to their larger MW. The negative charge of 361 HAAs favored their removal via electrostatic repulsion by the negatively charged NF membranes, 362 but due to their hydrophilicity they were not removed by adsorption and partitioning onto the NF 363 membranes as was the case with the hydrophobic THM molecules ${ }^{53,54}$. Some studies also used 364 reverse osmosis (RO) or even multistage $\mathrm{RO}$ to remove $\mathrm{DBPs}^{55,56}$, but one inevitable disadvantage 365 of RO lies in the unfavorable balance between minerals and pollutants. Here, we found that NF is 366 sufficiently capable of removing a great portion of DBPs, thus significantly decreasing the total 367 toxicity of DBPs (Figure 7c) while leaving some minerals in place. In comparing the two NF 368 membranes, the results suggest that using NF270 as a domestic treatment could be more effective 369 due to its comparable DBP removal rate, but nearly double water permeability compared to NF90 370 (SI, Table S5). 

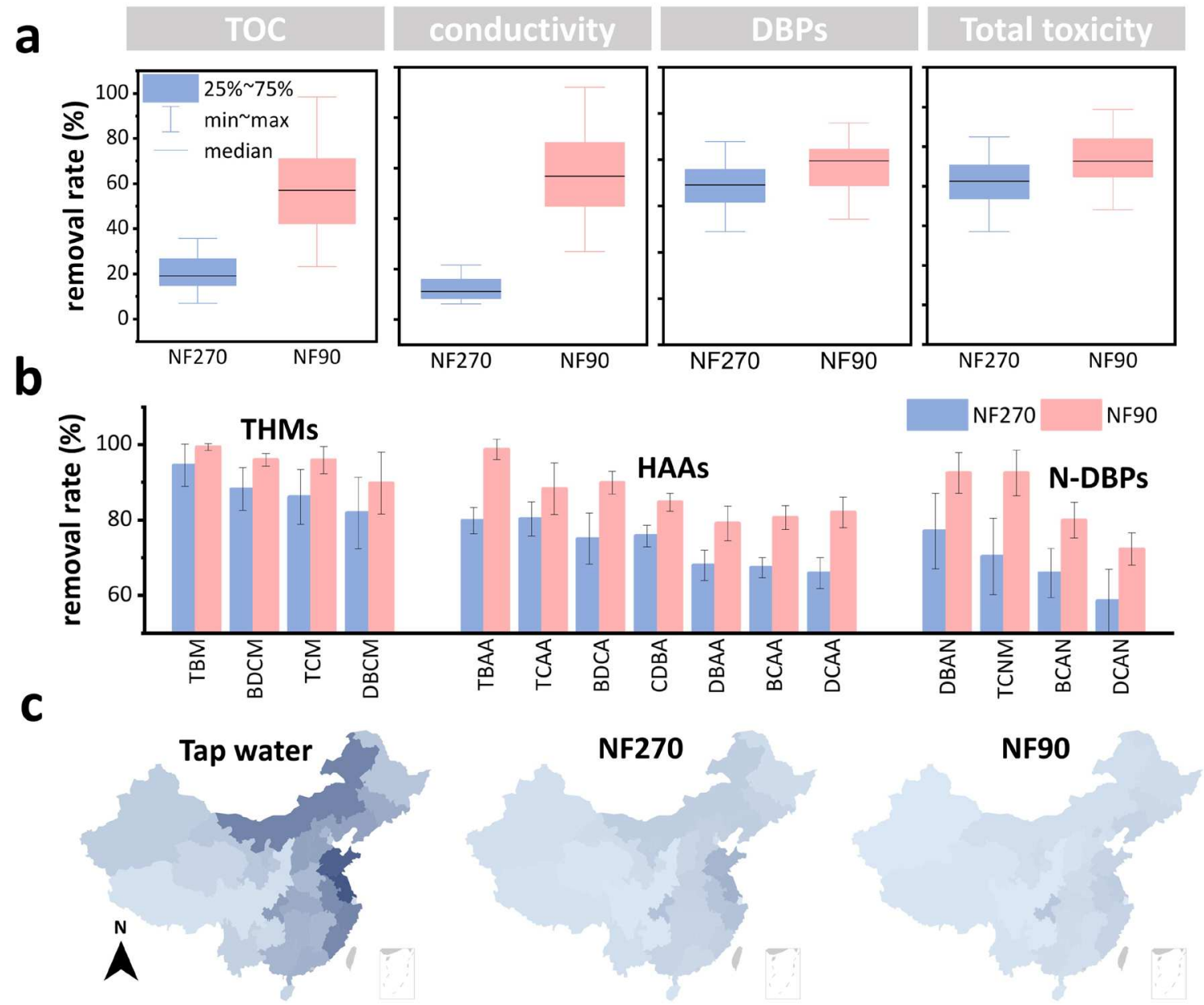

$6 \times 10^{-6}$

Figure 7. Water quality improvement by nanofiltration. (a) Removal rate of TOC, conductivity, DBPs and total toxicity by two NF membranes: NF270 ("loose" NF) and NF90 ("tight" NF). (b) Removal rate of different types of DBPs (THMs, trihalomethanes; HAAs, haloacetic acid; N-DBPs, nitrogen-containing DBPs) by the two NF membranes. Detailed information about these DBPs is given in Table S6. (c) Total toxicity of DBPs in tap water before (left) and after NF270 (middle) or after NF90 (right). The calculation of total toxicity was shown in Methods.

\section{Discussion}

This is one of the first studies to assess tap water quality at a large spatial scale and to discuss

381 the driving factors as well as the adverse health outcomes. The findings revealed a significant

382 variation of tap water quality across China in terms of organic content, background ions and 383 disinfection byproducts (DBPs). The results further demonstrate the influence of natural and 
anthropogenic factors on tap water quality, while also confirming the association between DBPs and specific cancers from the perspective of spatial distribution. In addition, the feasibility of nanofiltration (NF) to improve water quality was tested, suggesting that NF can be used as a point-

387 of-use treatment to reduce the health risks of DBP exposure without removing necessary minerals as RO does.

Based on the assessment of tap water from 103 cities, the spatial distribution pattern of tap water quality was identified. The total organic carbon (TOC) and conductivity in tap water are 391 closely related to water source, with precipitation playing an essential role in their spatial diversity,

392 especially for northern China where its annual precipitation of less than $800 \mathrm{~mm}$. Therefore, arid 393 and semi-arid regions face not only water shortages but also poor drinking water quality. The 394 South-to-North Water Diversion project conducted by the Chinese government provided a solution. 395 Our results suggest that the water diversion engineering works have not only significantly relieved 396 the water resource pressure on the Hai River Basin, but also improved the drinking water quality 397 in this region. The concentration of DBPs was significantly correlated with the organic content 398 (Figure S14). Therefore, the north-east (NE) region and the middle Changjiang River (MCR) 399 harbored a high concentration of DBPs, while the west regions (north-west (NW) and south-west 400 (SW)) faced less DBP exposure. However, the toxicity of DBPs was not only determined by the 401 DBP concentration, but was highly affected by their composition. Key areas with significantly 402 higher or lower DBP toxicity were identified. High toxic areas clustered at east coastal regions, 403 while low toxic areas were distributed at west regions. Moreover, we found that the total toxicity 404 of DBPs was strongly affected by anthropogenic factors such as economic strength and pollution 405 emission. Therefore, it is necessary to improve the coverage of advanced drinking water treatment 406 in economically developed cities, to make up for the problems of drinking water safety caused by 407 economic development.

408 While several alternative disinfectants have been proposed to reduce DBPs, chlorine-based 409 disinfection (i.e., chlorine, chloramine and chlorine dioxide) continues to be the mainstream 
410 disinfection method in drinking water treatment in China. Hence, chlorinated DBPs in drinking 411 water and their associated health risks will remain a long-term problem. Scientists have associated 412 DBP exposure to a variety of adverse health outcomes, including specific cancers (bladder, colon 413 and rectal), low birth weight, and miscarriages. Among these, bladder cancer has the most 414 consistent association with DBPs in previous studies. Our study confirmed that areas with high 415 DBPs had a significantly higher incidence of bladder cancer from a spatial distribution perspective, 416 but the results for colon and rectal cancer were not as significant as bladder cancer. It is worth 417 noting that although more than 600 emerging DBPs have been reported in the literature, less than 418100 have undergone quantitative occurrence or health effect studies ${ }^{57}$. Most of the epidemiological 419 studies used THMs and/or haloacetic acids (HAAs) to estimate DBPs exposure, but 420 epidemiological data related to emerging DBP exposure is particularly scarce. Therefore, it is still 421 unclear whether emerging DBPs have other health effects on humans, and whether the use of other 422 chlorine-containing disinfectants will enhance the formation of unregulated DBPs with higher 423 health risks.

424 The results in this study represent a first attempt to consider drinking water safety issues and 425 the pattern of spatial variation in tap water quality in terms of DBP occurrence on a national scale. 426 However, there are still some uncertainties that deserve further investigation. First, although we 427 tried to collect as many water samples as possible to provide accurate information on national tap 428 water quality, the spatial and temporal variations of DBPs in drinking water make it difficult to 429 estimate actual human exposure. Second, due to the lack of records, it is challenging to conduct 430 time series analysis and explore the evolution of tap water quality over time. High-resolution data 431 (both spatial and temporasl) can provide stronger evidence to identify the key factors affecting tap 432 water quality, and important data for researchers to reveal the relationship between tap water and 433 human health. Therefore, it is recommended that researchers and practitioners should cooperate to 434 perform more intensive and detailed surveys of DBPs and other contaminants at a national level, 435 and a database of drinking water quality should be established to provide data support for related 
studies.

\section{Materials and methods}

\section{Chemicals and materials}

440 Methyl tert-butyl ether (MTBE) and methanol were, respectively, liquid chromatography grade

441 and high-performance liquid chromatography (HPLC) grade; they were purchased from J.T. Baker,

442 USA. Anhydrous sodium sulfate $\left(\mathrm{Na}_{2} \mathrm{SO}_{4}\right)$, sulfuric acid $\left(\mathrm{H}_{2} \mathrm{SO}_{4}\right)$ and sodium bicarbonate

$443\left(\mathrm{NaHCO}_{3}\right)$ were obtained from Sinopharm Chemical Reagent Co., Ltd, China.

\section{Sample collection and nanofiltration}

445 Household tap water samples were collected from 103 cities, located within 31 administrative 446 provinces and eight regions (see SI, Figure S1) during March to April, 2021. At sampling points, 447 we collected as many samples as possible to ensure the reliability of the results. However, for some 448 remote areas, such as northwestern China, only a small number of principal cities (i.e. the capital 449 of each province) were sampled, as rural areas with low population densities typically have no 450 centralized water supply system. For each sampling point, two replicate water samples were 451 collected, and the tap faucets were not equipped with a filter or other water purification unit. Prior 452 to sampling, the faucet was opened for at least five minutes, the sample bottles were rinsed three 453 times and then filled to just overflowing. All collected samples were transferred to the laboratory 454 in ice packs as soon as possible, and stored at $4{ }^{\circ} \mathrm{C}$ before use.

455 Nanofiltration tests were conducted using flat sheet poly (piperazine-amide) (PA) membranes 456 (NF270 and NF90, RisingSun Membrane Technology (Beijing) Co., Ltd., China) in a dead-end 457 filtration apparatus (Amicon 8400, Millipore, USA). The properties of these two membranes are 458 given in the Supporting Information (Table S5). Before use, the membranes were immersed in 459 deionized (DI) water for at least 72 hours to remove organic residuals during production. The 460 operational applied pressure was set at 4 bar using high-purity nitrogen (99.99\%, Haike Corp., 
461 China). The filtrate was collected after filtering $100 \mathrm{~mL}$ tap water, in order to avoid the influence 462 of initial adsorption.

463

464

465

466

467

468

469

470

471

472

473

474

475

\section{Instrumental analysis}

A UV-visible spectrophotometer (UV-2600, Shimadzu, Japan) and a three-dimensional excitation-emission matrix (EEM) spectrofluorometer (F-4600FL, Hitachi, Japan) were used to characterize the chromophore and fluorescent organic substances in water samples, respectively. Total organic carbon (TOC) and conductivity were measured using a TOC analyzer (TOC-Vwp, Shimadzu, Japan) and a conductivity meter (FiveEasy Plus, Mettler Toledo, Switzerland). The concentration of metal ions was measured via Inductively Coupled Plasma Optical Emission Spectrometer (ICP-OES, Shimadzu, Japan) after microwave digestion.

DBP extraction methods followed the standard methods ${ }^{58,59}$, and details of these methods are described in the SI (Text S1). Each sample was prepared in duplicate. The concentration of DBPs was measured by gas chromatography (Clarus 590, PerkinElmer, U.S.) with an electron capture detector (ECD). Conditions for the analyses were as follows: (1) THMs and N-DBPs, injector temperature $200{ }^{\circ} \mathrm{C}$, column temperature $35{ }^{\circ} \mathrm{C}$ (holding four minutes) to $260{ }^{\circ} \mathrm{C}\left(10{ }^{\circ} \mathrm{C} / \mathrm{min}\right)$, detector temperature $290{ }^{\circ} \mathrm{C}$; (2) HAAs, injector temperature $200{ }^{\circ} \mathrm{C}$, column temperature $35{ }^{\circ} \mathrm{C}$ (holding four minutes) to $65^{\circ} \mathrm{C}\left(2{ }^{\circ} \mathrm{C} / \mathrm{min}\right)$, detector temperature $290{ }^{\circ} \mathrm{C}$.

\section{Data analysis}

Data concerning environmental stress factors were collected from different types of databases, including the China Statistical Yearbook, China Statistical Yearbook on Environment and others (SI, Table S4). The age standard rates (ASR) for bladder, colon and rectal cancers (SI, Table S2) were obtained from the China cancer registry annual report (2018). The toxicity of DBPs were calculated by summing the individual toxic potency-weighted DBP concentrations (Equation 1). The $\mathrm{LC}_{50}$ values were obtained from published literature ${ }^{47}$ and are provided in the Supplementary Information (Table S6). 


$$
\text { CHO cytotoxicity index }=\sum_{1}^{n} \frac{[\mathrm{DBP}]_{i}}{\mathrm{LC}_{50_{i}}}
$$
Macao, and Taiwan due to sample unavailability. Data analyses were performed with the $\mathrm{R}$ software (4.0.5). EEM data were corrected and the optical parameters (SI, Table S3) were calculated from UV absorbance and corrected EEM data via the R package (named staRdom). Additionally, EEM data were divided into five regions and the volumetric integration under the 492 EEM within each region was calculated according to previous study ${ }^{60}$. Principal component 493 analysis (PCA) and PERMANOVA were performed by using the R package (named vegan) 494 Function $\mathrm{lm}$ from the $\mathrm{R}$ package statistics was used to conduct the linear regression. A partial 495 Mantel test was performed to examine the correlation between location and tap water qualities 496 using the R package (named psych). Partial least squares path modeling (PLS-PM) analysis was 497 performed via R package (named plspm) to explore the direct and indirect relationships among 498 environmental variables and water qualities.

Geoda (1.18.0) was used to perform spatial autocorrelation analysis for the 31 sampled 500 provinces ${ }^{61}$. Moran's I statistic is the most commonly used indicator of global spatial 501 autocorrelation, which is a cross-product statistic between a variable and its spatial lag, with the 502 variable expressed in deviations from its mean. For an observation at location i, this is expressed 503 as $z_{i}=x_{i}-\bar{x}$, where $\bar{x}$ is the mean of variable $\mathrm{x}$.

504 Moran's I statistic is then calculated as follows:

$$
I=\frac{\sum_{i} \sum_{j} w_{i j} z_{i} \cdot z_{j} / S_{0}}{\sum_{i} z_{i}^{2} / n}
$$
with $w_{i j}$ as the elements of the spatial weight matrix, $S_{0}=\sum_{i} \sum_{j} w_{i j}$ as the sum of all the 507 weights, and $n$ as the number of observations.

508 Global spatial autocorrelation is designed to reject the null hypothesis of spatial randomness in 509 favor of an alternative of clustering. The Local Moran statistic was further performed to identify 
510 local clusters and local spatial outliers. It should be noted that the cluster maps are not the actual

511 clusters, but the cores of a cluster. In contrast, in the case of spatial outliers, they are the actual

512 locations of interest. More information can be found on the statistical software website

513 (https://geodacenter.github.io/documentation.html).

\section{$515 \quad$ References}

5161 Prüss-Ustün, A. et al. Burden of disease from inadequate water, sanitation and hygiene in low517 and middle-income settings: a retrospective analysis of data from 145 countries. Trop Med Int 518 Health 19, 894-905, doi:https://doi.org/10.1111/tmi.12329 (2014).

5192 Bain, R. et al. Accounting for water quality in monitoring access to safe drinking-water as part 520 of the Millennium Development Goals: lessons from five countries. Bulletin of the World Health 521 Organization 90, 228-235A (2012).

5223 Maqbool, T. et al. Exploring the relative changes in dissolved organic matter for assessing the water quality of full-scale drinking water treatment plants using a fluorescence ratio approach.

524 Water Research 183, 116125, doi:https://doi.org/10.1016/j.watres.2020.116125 (2020).

$4 \mathrm{Li}, \mathrm{C}$. et al. Tracking changes in composition and amount of dissolved organic matter throughout drinking water treatment plants by comprehensive two-dimensional gas chromatography-quadrupole mass spectrometry. Science of The Total Environment 609, 123-131, doi:https://doi.org/10.1016/j.scitotenv.2017.07.147 (2017).

5295 David L. Sedlak, U. v. G. The Chlorine Dilemma. Science 331, 1, doi:DOI: 10.1126/science.1196397 (2011).

5316 Shannon, M. A. et al. Science and technology for water purification in the coming decades. Nature 452, 301-310, doi:10.1038/nature06599 (2008).

5337 Li, X.-F. \& Mitch, W. A. Drinking Water Disinfection Byproducts (DBPs) and Human Health 534 Effects: Multidisciplinary Challenges and Opportunities. Environmental Science \& Technology 52, 535 1681-1689, doi:10.1021/acs.est.7b05440 (2018).

5368 Richardson, S. D., Plewa, M. J., Wagner, E. D., Schoeny, R. \& DeMarini, D. M. Occurrence, 537 genotoxicity, and carcinogenicity of regulated and emerging disinfection by-products in drinking 538 water: A review and roadmap for research. Mutation Research/Reviews in Mutation Research 636, 539 178-242, doi:https://doi.org/10.1016/j.mrrev.2007.09.001 (2007).

5409 Costet, N. et al. Water disinfection by-products and bladder cancer: is there a European 541 specificity? A pooled and meta-analysis of European case-control studies. Occupational and 
environmental medicine 68, 379-385, doi:10.1136/oem.2010.062703 (2011).

$543 \quad 10$ Hao, X., Chen, G. \& Yuan, Z. Water in China. Water Research 169, 115256, 544 doi:https://doi.org/10.1016/j.watres.2019.115256(2020).

$54511 \mathrm{Li}, \mathrm{Z}$. et al. Occurrence and Distribution of Disinfection Byproducts in Domestic Wastewater Effluent, Tap Water, and Surface Water during the SARS-CoV-2 Pandemic in China. Environmental Science \& Technology 55, 4103-4114, doi:10.1021/acs.est.0c06856 (2021).

12 Zhou, X. et al. Factors influencing DBPs occurrence in tap water of Jinhua Region in Zhejiang Province, China. Ecotoxicology and Environmental Safety 171, 813-822, doi:https://doi.org/10.1016/j.ecoenv.2018.12.106 (2019).

13 Wang, C. et al. Occurrence, migration and health risk of phthalates in tap water, barreled water and bottled water in Tianjin, China. Journal of Hazardous Materials 408, 124891, doi:https://doi.org/10.1016/j.jhazmat.2020.124891 (2021).

14 Malliarou, E., Collins, C., Graham, N. \& Nieuwenhuijsen, M. J. Haloacetic acids in drinking water in the United Kingdom. Water Research 39, 2722-2730, doi:https://doi.org/10.1016/j.watres.2005.04.052 (2005).

$557 \quad 15$ Krasner, S. W. et al. Occurrence of a New Generation of Disinfection Byproducts. Environmental Science \& Technology 40, 7175-7185, doi:10.1021/es060353j (2006).

55916 Ding, H. et al. Occurrence, profiling and prioritization of halogenated disinfection by560 products in drinking water of China. Environmental Science: Processes \& Impacts 15, 1424-1429, doi:10.1039/C3EM00110E (2013).

17 Ding, Y. et al. Chemodiversity of Soil Dissolved Organic Matter. Environmental Science \& Technology 54, 6174-6184, doi:10.1021/acs.est.0c01136 (2020).

18 Zhu, J. et al. Carbon stocks and changes of dead organic matter in China's forests. Nature Communications 8, 151, doi:10.1038/s41467-017-00207-1 (2017).

19 Jiao, N. et al. Correcting a major error in assessing organic carbon pollution in natural waters. Science Advance 7, eabc7318, doi:10.1126/sciadv.abc7318 \%J Science Advances (2021).

20 Lu, Y. et al. Forty years of reform and opening up: China's progress toward a sustainable path. Science Advance 5, eaau9413, doi:10.1126/sciadv.aau9413 \%J Science Advances (2019).

57021 Tong, Y. et al. Improvement in municipal wastewater treatment alters lake nitrogen to phosphorus ratios in populated regions. Proceedings of the National Academy of Sciences 117, 11566, doi:10.1073/pnas.1920759117 (2020). Hyde. 
57723 Chen, H.-C. \& Du, P. Potential Ecological Benefits of the Middle Route for the South-

578 North Water Diversion Project. Tsinghua Science \& Technology 13, 715-719, 579 doi:https://doi.org/10.1016/S1007-0214(08)70113-5 (2008).

58024 Tong, Y. et al. Decline in Chinese lake phosphorus concentration accompanied by shift in sources since 2006. Nature Geoscience 10, 507-511, doi:10.1038/ngeo2967 (2017).

$582 \quad 25$ Fang, C. et al. Characterization of Dissolved Organic Matter and Its Derived Disinfection 583 Byproduct Formation along the Yangtze River. Environmental Science \& Technology, 584 doi:10.1021/acs.est.1c02378 (2021).

58526 Sanchez, N. P., Skeriotis, A. T. \& Miller, C. M. Assessment of dissolved organic matter fluorescence PARAFAC components before and after coagulation-filtration in a full scale water treatment plant. Water Research 47, 1679-1690, doi:https://doi.org/10.1016/j.watres.2012.12.032 (2013).

58927 Wang, S. et al. Reduced sediment transport in the Yellow River due to anthropogenic changes. Nature Geoscience 9, 38-41, doi:10.1038/ngeo2602 (2016).

28 Tan, W.-F. et al. Soil inorganic carbon stock under different soil types and land uses on the Loess Plateau region of China. CATENA 121, 22-30, doi:https://doi.org/10.1016/j.catena.2014.04.014 (2014).

29 Wang, Y., Li, Y., Ye, X., Chu, Y. \& Wang, X. Profile storage of organic/inorganic carbon in soil: From forest to desert. Science of The Total Environment 408, 1925-1931, doi:https://doi.org/10.1016/j.scitotenv.2010.01.015 (2010).

30 Bond, T., Huang, J., Templeton, M. R. \& Graham, N. Occurrence and control of nitrogenous disinfection by-products in drinking water - A review. Water Research 45, 4341-4354, doi:https://doi.org/10.1016/j.watres.2011.05.034 (2011).

60031 Yang, M. \& Zhang, X. Comparative Developmental Toxicity of New Aromatic Halogenated DBPs in a Chlorinated Saline Sewage Effluent to the Marine Polychaete Platynereis dumerilii. Environmental Science \& Technology 47, 10868-10876, doi:10.1021/es401841t (2013).

32 Liu, J. \& Zhang, X. Comparative toxicity of new halophenolic DBPs in chlorinated saline 605 haloaliphatic ones. Water Research 65, 64-72, doi:https://doi.org/10.1016/j.watres.2014.07.024 606 (2014).

60733 Zeng, T., Plewa, M. J. \& Mitch, W. A. N-Nitrosamines and halogenated disinfection 608 byproducts in U.S. Full Advanced Treatment trains for potable reuse. Water Research 101, 176609 186, doi:https://doi.org/10.1016/j.watres.2016.03.062 (2016).

61034 Pan, Y. \& Zhang, X. Four Groups of New Aromatic Halogenated Disinfection Byproducts: 611 Effect of Bromide Concentration on Their Formation and Speciation in Chlorinated Drinking 
612 Water. Environmental Science \& Technology 47, 1265-1273, doi:10.1021/es303729n (2013).

$613 \quad 35$ Szczuka, A. et al. Regulated and unregulated halogenated disinfection byproduct 614 formation from chlorination of saline groundwater. Water Research 122, 633-644, 615 doi:https://doi.org/10.1016/j.watres.2017.06.028 (2017).

61636 de Vera, G. A., Keller, J., Gernjak, W., Weinberg, H. \& Farré, M. J. Biodegradability of 617 DBP precursors after drinking water ozonation. Water Research 106, 550-561, 618 doi:https://doi.org/10.1016/j.watres.2016.10.022 (2016).

61937 Fu, J. et al. Removal of disinfection byproduct (DBP) precursors in water by two-stage 620 biofiltration treatment. Water Research 123, 224-235, 621 doi:https://doi.org/10.1016/j.watres.2017.06.073 (2017).

62238 Su, Z., Liu, T., Yu, W., Li, X. \& Graham, N. J. D. Coagulation of surface water: 623 Observations on the significance of biopolymers. Water Research 126, 144-152, 624 doi:https://doi.org/10.1016/j.watres.2017.09.022 (2017).

62539 Chuang, Y.-H. et al. Pilot-scale comparison of microfiltration/reverse osmosis and 626 ozone/biological activated carbon with UV/hydrogen peroxide or UV/free chlorine AOP treatment 627 for controlling disinfection byproducts during wastewater reuse. Water Research 152, 215-225, 628 doi:https://doi.org/10.1016/j.watres.2018.12.062 (2019).

62940 Hua, Z. et al. DBP alteration from NOM and model compounds after UV/persulfate 630 treatment with post chlorination. Water Research 158, 237-245, 631 doi:https://doi.org/10.1016/j.watres.2019.04.030 (2019).

63241 Phungsai, P., Kurisu, F., Kasuga, I. \& Furumai, H. Molecular characteristics of dissolved 633 organic matter transformed by $\mathrm{O} 3$ and $\mathrm{O} 3 / \mathrm{H} 2 \mathrm{O} 2$ treatments and the effects on formation of 634 unknown disinfection by-products. Water Research 159, 214-222, 635 doi:https://doi.org/10.1016/j.watres.2019.05.002 (2019).

63642 Waller, K., Swan, S. H., DeLorenze, G. \& Hopkins, B. Trihalomethanes in drinking water 637 and spontaneous abortion. Epidemiology (Cambridge, Mass.) 9, 134-140 (1998).

63843 Wright, J. M., Evans, A., Kaufman, J. A., Rivera-Núñez, Z. \& Narotsky, M. G. 639 Disinfection By-Product Exposures and the Risk of Specific Cardiac Birth Defects. Environ Health 640 Perspect 125, 269-277, doi:10.1289/ehp103 (2017).

64144 Morris, R. D., Audet, A. M., Angelillo, I. F., Chalmers, T. C. \& Mosteller, F. Chlorination, 642 chlorination by-products, and cancer: a meta-analysis. American journal of public health 82, 955643 963, doi:10.2105/ajph.82.7.955 (1992).

$644 \quad 45$ Benmarhnia, T., Delpla, I., Schwarz, L., Rodriguez, M. J. \& Levallois, P. Heterogeneity 645 in the Relationship between Disinfection By-Products in Drinking Water and Cancer: A Systematic 646 Review. International journal of environmental research and public health $\mathbf{1 5}$, 
doi:10.3390/ijerph15050979 (2018).

64846 Rahman, M. B., Driscoll, T., Cowie, C. \& Armstrong, B. K. Disinfection by-products in drinking water and colorectal cancer: a meta-analysis. International Journal of Epidemiology 39, 733-745, doi:10.1093/ije/dyp371 \%J International Journal of Epidemiology (2010).

65147 Lau, S. S. et al. Assessing Additivity of Cytotoxicity Associated with Disinfection 652 Byproducts in Potable Reuse and Conventional Drinking Waters. Environmental Science \& 653 Technology 54, 5729-5736, doi:10.1021/acs.est.0c00958 (2020).

65448 Yang, Y. et al. Toxic Impact of Bromide and Iodide on Drinking Water Disinfected with 655 Chlorine or Chloramines. Environmental Science \& Technology 48, 12362-12369, doi:10.1021/es503621e (2014).

65749 Chen, Y., Li, J. \& Tan, Q. Trends of production, consumption and environmental 658 emissions of Decabromodiphenyl ether in mainland China. Environmental Pollution 260, 114022, 659 doi:https://doi.org/10.1016/j.envpol.2020.114022 (2020).

66050 Liu, L. et al. Spatio-temporal variations and input patterns on the legacy and novel brominated flame retardants (BFRs) in coastal rivers of North China. Environmental Pollution 283, 117093, doi:https://doi.org/10.1016/j.envpol.2021.117093 (2021).

66351 Wang, X. et al. Bioconcentration, Biotransformation, and Thyroid Endocrine Disruption 664 of Decabromodiphenyl Ethane (Dbdpe), A Novel Brominated Flame Retardant, in Zebrafish Larvae. Environmental Science \& Technology 53, 8437-8446, doi:10.1021/acs.est.9b02831 (2019).

66652 Chen, B., Jiang, J., Yang, X., Zhang, X. \& Westerhoff, P. Roles and Knowledge Gaps of 667 Point-of-Use Technologies for Mitigating Health Risks from Disinfection Byproducts in Tap Water: 668 A Critical Review. Water Research 200, 117265, doi:https://doi.org/10.1016/j.watres.2021.117265 669 (2021).

67053 Nghiem, L. D., Schäfer, A. I. \& Elimelech, M. Removal of Natural Hormones by 671 Nanofiltration Membranes: Measurement, Modeling, and Mechanisms. Environmental Science \& 672 Technology 38, 1888-1896, doi:10.1021/es034952r (2004).

67354 Nghiem, L. D., Schäfer, A. I. \& Elimelech, M. Nanofiltration of Hormone Mimicking 674 Trace Organic Contaminants. Separation Science and Technology 40, 2633-2649, 675 doi:10.1080/01496390500283340 (2005).

67655 Wang, L., Sun, Y. \& Chen, B. Rejection of haloacetic acids in water by multi-stage reverse 677 osmosis: Efficiency, mechanisms, and influencing factors. Water Research 144, 383-392, 678 doi:https://doi.org/10.1016/j.watres.2018.07.045 (2018).

67956 Chen, B., Zhang, C., Wang, L., Yang, J. \& Sun, Y. Removal of disinfection byproducts in 680 drinking water by flexible reverse osmosis: Efficiency comparison, fates, influencing factors, and 681 mechanisms.

Journal of Hazardous Materials

401, 123408, 
682 doi:https://doi.org/10.1016/j.jhazmat.2020.123408 (2021).

68357 Hebert, A. et al. Innovative method for prioritizing emerging disinfection by-products 684 (DBPs) in drinking water on the basis of their potential impact on public health. Water Research 685 44, 3147-3165, doi:https://doi.org/10.1016/j.watres.2010.02.004 (2010).

68658 EPA., U. S. Method 552.3: Determination of haloacetic acids and dalapon in drinking 687 water by liquid-liquid microextraction, derivatization, and Gas chromatography with electron 688 capture detection. EPA 815-B-03-002. Revision 1.0. (2003).

68959 EPA., U. S. Method 551.1: Determination of Chlorination Disinfection Byproducts, 690 Chlorinated Solvents, and Halogenated Pesticides/Herbicides in Drinking Water by Liquid-Liquid 691 Extraction and Gas Chromatography With Electron-Capture Detection, Revision 1.0. . (1995).

69260 Chen, W., Westerhoff, P., Leenheer, J. A. \& Booksh, K. Fluorescence 693 Excitation-Emission Matrix Regional Integration to Quantify Spectra for Dissolved Organic 694 Matter. Environmental Science \& Technology 37, 5701-5710, doi:10.1021/es034354c (2003).

69561 Anselin, L., Syabri, I. \& Smirnov, O. Visualizing Multivariate Spatial Correlation with 696 Dynamically Linked Windows. New Tools for Spatial Data Analysis: Proceedings of the Specialist 697 Meeting; Santa Barbara (2002). 


\section{Supplementary Files}

This is a list of supplementary files associated with this preprint. Click to download.

- LiuYuetalNatureSustSupportingInfoDec.13.2021.docx 